\title{
Effect of antimicrobials on mechanical, barrier and optical properties of corn starch based self-supporting edible film
}

\author{
Tanima Chowdhury ${ }^{a}$ And Madhusweta Das ${ }^{\mathrm{a}^{*}}$ \\ ${ }^{a}$ Department of Agricultural and Food Engineering - Indian Institute of Technology, Kharagpur - 721302, India \\ ${ }^{*}$ Corresponding author \\ madhu@agfe.iitkgp.ernet.in \\ TEL: +91-3222-283108(O), $283113(\mathrm{R})$ \\ FAX: $+91-3222-282244 / 255303$
}

Received: 20 December 2012; Published online: 18 October 2013

\begin{abstract}
Antimicrobials like potassium sorbate, sodium propionate, and benzoic acid were incorporated in corn starch based formulation to investigate their effect on mechanical, water vapour barrier and optical properties of the developed self supporting edible film. The film was prepared by casting technique. When incorporated at $1.40 \%$ and above, potassium sorbate decreased the tensile strength (about $22 \%$ ) and increased the elongation (about 55\%) of control film; whereas, it increased the water vapour permeability by $15 \%$ only when added at $2.66 \%$. At $2.66 \%$, benzoic acid reduced the tensile strength by $24 \%$ and sodium propionate increased elongation by $17 \%$. These two antimicrobials did not change the water vapour permeability. However, all the three antimicrobials adversely affected the optical properties by decreasing the whiteness index, increasing yellowness index, and reducing the surface gloss, with potassium sorbate showing the maximum effect. Among the three antimicrobials, sodium propionate appeared to be the best with minimum deterioration of film properties.
\end{abstract}

Keywords: edible film; antimicrobials; corn starch film 


\section{Nomenclature}

$\begin{array}{ll}\text { ANOVA } & \text { Analysis of variance } \\ \text { BA } & \text { Benzoic acid } \\ \text { \% E } & \text { Percent elongation } \\ \text { HPMC } & \text { Hydroxypropylmethylcellulose } \\ \text { PS } & \text { Potassium sorbate } \\ \text { RH } & \text { Relative humidity } \\ \text { SP } & \text { Sodium propionate } \\ \text { SSEF } & \text { Self-supporting edible film } \\ \text { TS } & \text { Tensile strength } \\ \text { WI } & \text { Whiteness index } \\ \text { WVP } & \text { Water vapour permeability } \\ \text { Z\% } & \text { Brightness index }\end{array}$

\section{Introduction}

Food grade ingredients like carbohydrates, proteins, lipids and plasticizers, in different combinations can be cast into self-supporting edible films (SSEF) aiming for several food quality control purposes to improve shelf-life. The hydrocolloids that have been used for this purpose include polysaccharides like celluloses, starches, and their derivatives, seaweed extracts, pectins, gums, chitosan, and different proteins. Recently starch based SSEF are being considered because of their desirable physical characteristics such as being transparent, odorless, tasteless, semi-permeable to $\mathrm{CO}_{2}$ and resistant to $\mathrm{O}_{2}$ passage (Nisperos-Carriedo, 1994; Vásconez, Flores, Campos, Alvarado, \& Gerschenson, 2009). Starch is abundantly available and cheap. SSEF that additionally contains an antimicrobial in its formulation can be used as an active packaging wrapper on fresh/minimally processed fruits and vegetables where the antimicrobial diffuses into the interior and extends the shelf life of the contents (Das \& Namitha, 2010; Durango, Soares, \& Andrade, 2006; Garcia, Martino, \& Zaritzky, 1998). The film can effectively preserve the organoleptic and nutritional qualities of the wrapped food (Campos, Gerschenson, \& Flores, 2011). These antimicrobial-containing films can also be layered within fabricated multilayered foods like wafers, cakes, pastries, etc. to retard the growth of microbes at particular sites. Through such techniques, addition of the antimicrobial to the whole of the food mass can be avoided (Salleh, Muhamad, \& Khairuddin, 2009; Valencia-Chamorro, Palou, Del Rio, \& Perez Gago, 2008).

Self-supporting edible films have excellent aroma barrier properties (Das \& Bal, 1999), and therefore can preserve the quality of aromacontaining materials when packaged with these films. Moreover, the water dispersible character of these films facilitates packaging of specific food additives in separate pouches which can go into the cooking medium, dispersing both additives and pouches together. This helps the addition of pre-measured additives for better quality control in food processing as well as a reduction in conventional petroleum-based synthetic pouch disposal (Das \& Bal, 1999; Ninomiya, Suzuki, \& Ishii, 1992; Schou et al., 2005; Patel \& Thanawala, 2008; Yang, Fuisz, Myers, \& Fuisz, 2004). Nonetheless, as they are made from edible materials, on exposure to the open environment SSEF without any antimicrobial additive are susceptible to infection by air-borne microbes, particularly in humid conditions. So, besides providing active packaging, the incorporation of antimicrobial preservatives into the film may become essential for stability of the film itself (Chowdhury \& Das, 2010). However, such addition should not bring about any detrimental effects to film properties. Several studies have reported the efficacy of essential oils and other natural antimicrobials in different starch based formulations towards the antimicrobial potency of the film as well 
as the physical properties (Fazilah, Maizura, \& Norziah, 2006; Khairuddin, Razi, Radhiah, \& Muhamad, 2005; Kechichian, Ditchfield, Veiga-Santos, \& Tadini, 2010; Maizura, Fazilah, Norziah, \& Karim, 2007; Salleh \& Muhamad, 2007). Some low molecular weight synthetic organic acids (acetic, benzoic, lactic, propionic, and sorbic acids) and their salts may also be incorporated for antimicrobial activity in edible films (Valencia-Chamorro et al., 2008); an added advantage is that such antimicrobials are low cost. However, Ofman, Campos, and Gerschenson (2004) observed that such low molecular weight preservatives can form intermolecular complexes and modify film properties, depending on their concentration and chemical characteristics as well as on the type of starch used in film matrix. They reported that even low levels of ionic compounds affect potato starch gel, while cassava starch remains insensitive. Recently, Flores, Fama, Rojas, Goyanes, and Gerschenson (2007) concluded that potassium sorbate at a level of $6 \%$ in tapioca starch affected the solubility, colour and mechanical properties of films. Shen, $\mathrm{Wu}$, Chen, and Zhao (2010) studied the effect of up to $15 \%$ potassium sorbate on mechanical properties and water vapour permeability of sweet potato starch film. Fama, Rojas, Goyanes, and Gerschenson (2005) indicated a lowering of crystallinity in tapioca starch film with addition of $6 \%$ potassium sorbate. However, reports on the addition of potassium sorbate to corn starch films, and addition of sodium propionate and benzoic acid to starch films in general are limited. Such preservatives also modify other polysaccharide based films (Valencia-Chamorro et al., 2008).

The objective of the present work was to investigate the effect of incorporation of the antimicrobials benzoic acid (BA), sodium propionate (SP), and potassium sorbate (PS) in corn starch based film formulation on physico-mechanical properties of the final SSEF.

\section{Materials and Methods}

\subsection{Materials}

Corn starch (amylose content 21.7\%) was procured from local market. Hydroxypropylmethylcellulose (HPMC), BA, SP, and PS, polyethylene glycol (400) and glycerol (87\%) were of laboratory or Analar grade. The water used was glass distilled.

\section{$2.2 \quad$ Film preparation}

A blend containing corn starch (5.75 g), hydroxypropylmethylcellulose $(0.25 \mathrm{~g})$, and plasticizers (glycerol $(1.46 \mathrm{ml})$, polyethylene glycol $(1 \mathrm{ml})$ and water $(77.54 \mathrm{ml})$ ), and antimicrobial agents at the levels of $0,0.1,0.2,0.3,0.4,0.7,1.4,2.0$ and $2.66 \%(\mathrm{w} / \mathrm{w}$, on the basis of wet weight of polymer comprising starch plus HPMC i.e., total polymer weight of $6 \mathrm{~g}$ ) was gelatinized, spread on a polypropylene plate and dried to obtain the SSEF. Details of film casting have been described elsewhere (Chowdhury \& Das, 2010).

\section{$2.3 \quad$ Film conditioning}

All films were conditioned at $50 \%$ relative humidity $(\mathrm{RH})$ at $25 \pm 1{ }^{\circ} \mathrm{C}$ for at least $48 \mathrm{~h}$ prior to measurement of different properties. This helped to maintain film water activity $\left(\mathrm{a}_{w}\right)$ at 0.5 during measurement.

\section{$2.4 \quad$ Film thickness}

Thickness of film sample was measured at least at 5 random positions by a hand dial thickness gauge, model 7301 (Mitutoyo Co., Tokyo, Japan) with an accuracy of $0.01 \mathrm{~mm}$. The mean value was calculated.

\subsection{Mechanical properties}

Peak tensile strength (TS) and percent elongation at break (\% E) were estimated according to 
ASTM D882-97 using an Instron Universal Testing Machine (model 1011; Instron Corp., Canton, MA, USA). Rectangular pieces of the film were cut both vertically (along the web) and horizontally (perpendicular to the web) (5 replications of each) having a dimension of $100 \mathrm{~mm}$ gauge length and breadth of $10 \mathrm{~mm}$. The cut film was conditioned and then pulled apart at a speed of $10 \mathrm{~mm} / \mathrm{min}$. TS and $\% \mathrm{E}$ were obtained directly from the machine, using the average thickness.

\subsection{Water vapour permeability}

Water vapour permeability (WVP) of the film was determined by the gravimetric method using a cup (Shen et al., 2010). The cup contained distilled water occupying $\approx 50 \%$ of its volume. The film, cut in the form of circular disc, was completely sealed to mouth of the cup covering the aperture. This maintained $100 \%$ RH inside the cup. The cup was then placed inside a desiccator maintained at $50 \% \mathrm{RH}$. The desiccator was kept at $25 \pm 1^{\circ} \mathrm{C}$ in an incubator. Thus a fixed $\mathrm{RH}$ gradient $100 \% / 50 \%$ was maintained across the film. Initial weight of the cup and the weight after 24 $\mathrm{h}$ were recorded, and WVP value was calculated using Eq. 1.

$$
\mathrm{WVP}\left(\mathrm{g} \cdot \mathrm{mm} / \mathrm{kPa} \cdot \mathrm{m}^{2} \cdot \mathrm{h}\right)=\frac{\left(W_{1}-W_{2}\right) X}{\left(P_{A 1}-P_{A 2}\right) A t}
$$

where $\mathrm{W}_{1}$ is the initial weight of the cup $(\mathrm{g})$, $\mathrm{W}_{2}$ is the final weight of the cup (g), $\mathrm{X}$ is the film thickness $(\mathrm{mm}), \mathrm{P}_{A 1}$ is the partial pressure at $100 \% \mathrm{RH}(\mathrm{kPa}), \mathrm{P}_{A 2}$ is the partial pressure at $50 \% \mathrm{RH}(\mathrm{kPa}), \mathrm{A}$ is the area of the exposed film $\left(\mathrm{m}^{2}\right)$ and $\mathrm{t}$ is the time $(\mathrm{h})$ during which the change in weight had taken place. The measurement was done in three replications.

\section{$2.7 \quad$ Optical properties}

Whiteness index (WI), an estimate of the degree of whiteness, yellowness index (YI), an estimate of yellowness usually arising from product degradation by light, chemical changes etc., brightness index (Z\%) measuring brightness of a colour, that is the amount of light it reflects (the more it reflects the brighter it will be), and opacity, indicating the cloudiness of material, were all measured in a Hunter Lab Color Flex ${ }^{R}$ EZ (Reston, Virginia, United States) using D65 illuminant and $10^{\circ}$ observer angle. The film cut in the form of circular disc, after conditioning, was placed on a white plate for measuring WI, YI, and Z\%; for opacity, the sample was placed consecutively on white and black plates. Five replications were performed following the standard methods as suggested in the manual.

\subsection{Statistical analysis}

The treatment effect of the concentration of antimicrobials on film properties was determined by analysis of variance (ANOVA) (Gomez \& Gomez, 1984) for single factor experiment with completely randomized design with equal replications. Least significant differences (LSD; confidence level $\mathrm{P}<0.05$ and $\mathrm{P}<0.01$ ) were also evaluated (Gomez \& Gomez, 1984). All the statistical calculations were done using Microsoft Excel (Microsoft Inc., 2007).

\section{Results and Discussion}

\subsection{Mechanical properties}

The mechanical properties (TS and \% E) of the films were almost similar for the horizontally and vertically cut samples. Hence, irrespective of the direction of cut the average of all 10 replications was considered for analysis.

Figure 1 shows the effect of antimicrobial concentrations in percent $(\mathrm{w} / \mathrm{w})$ of the polymer that comprised corn starch and HPMC, on the tensile strength of the prepared SSEF. It was observed that incorporation of BA up to $2.00 \%$ did not show $(\mathrm{P}>0.05)$ any effect on TS of the control film $(19.580 \pm 0.004 \mathrm{MPa})$, however, when increased to $2.66 \%$, TS decreased significantly $(\mathrm{P}<0.01)$ to $14.845 \pm 1.760 \mathrm{MPa}(24.18 \%$ decrease). For the entire range of concentration, SP did not change $(\mathrm{P}>0.05)$ the TS. A similar lack of effect of SP on the TS was also observed for HPMC-lipid film at $\mathrm{a}_{w}$ of 0.5 by ValenciaChamorro et al. (2008). When PS was added at $1.40 \%$, a significant $(\mathrm{P}<0.01)$ decrease in TS from that of control was obtained; with higher concentrations, however, there was no further 
change (mean of $15.247 \pm 0.025 \mathrm{MPa}, \approx 22.13 \%$ decrease from control). The lowering of TS in case of BA and PS, at $2.66 \%$ and $1.40 \%$ respectively, may indicate an interaction of these antimicrobials with corn starch-HPMC-plasticizer network which probably decreases the cohesive force of the film. According to Shen et al. (2010), the TS (at $\mathrm{a}_{w} \approx 0.5$ ) of sweet potato starch film decreases progressively when addition of PS is over $5 \%$ of the polymer. Flores et al. (2007) observed that addition of PS to $6 \%$ of tapioca starch significantly reduced the TS (at $\mathrm{a}_{w}$ of 0.5 ) of the film and such reduction in TS is described as a plasticizing effect of sorbate on the starch molecule. However, Ofman et al. (2004) observed that PS and sodium benzoate at $2.85 \%$ of tapioca starch does not interact with starch at $\mathrm{a}_{w}$ less than 0.5. Fama et al. (2005) indicated that tapioca starch film without PS has $36 \%$ crystallinity whereas film with $6 \%$ PS of starch has $12 \%$ crystallinity, indicating an interaction of PS with tapioca starch. Thus, the response of corn starch film towards the reduction of the TS occurs at much lower concentration of PS than that of other starches. It is also pertinent to mention that TS values as shown in Figure 1 of the corn starch based films are comparable to the tensile strength of edible films developed from other polymers as reported by Campos et al. (2011).

Figure 2 shows the changes in elongation at break $(\% \mathrm{E})$ of the films versus the antimicrobial concentration. For the whole range of concentrations, BA did not affect $(\mathrm{P}>0.05)$ elongation value of the control film $(2.390 \pm 0.493 \%)$. For $\mathrm{SP}$, significant $(\mathrm{P}<0.05)$ change to $2.810 \pm 0.762 \%$ $(\approx 17.57 \%$ increase $)$ was noticed only at $2.66 \%$. Addition of $1.40 \%$ PS increased \% E of control film to a significantly higher $(\mathrm{P}<0.01)$ value, with no significant changes thereafter. Thus, PS at a level of $1.40 \%$ and higher caused an increase in the elongation to an average value of $3.716 \pm 0.335 \%$ i.e., $55.48 \%$ increase compared to that of control. According to Valencia-Chamorro et al. (2008), the benzene ring of sodium benzoate adversely affects the flexibility of polymeric film, whereas PS can penetrate more easily because of its straight chain structure so lowering TS and increasing \% E. Cagri, Ustunol, and Ryser (2001) also reported the similar behavior of $\mathrm{TS}$ and $\% \mathrm{E}$ in their study of whey pro- tein isolate films containing stearic acid (straight chain structure) and $p$-aminobenzoic acid (benzene ring).

\subsection{Water vapour permeability}

The effect of antimicrobials on WVP of the films is shown in Figure 3. The incorporation of BA and SP over the whole range of concentration did not affect $(\mathrm{P}>0.05)$ the WVP of corn starch films. However, addition of PS only at $2.66 \%$ significantly $(\mathrm{P}<0.05)$ increased the WVP value from $0.841 \pm 0.005$ g.mm $/ \mathrm{m}^{2} . \mathrm{kPa} . \mathrm{h}$ (control film) to $0.968 \pm 0.183$ g.mm $/ \mathrm{m}^{2} . \mathrm{kPa} . \mathrm{h}$ $(\approx 15.1 \%$ increase); below this level of PS, the WVP remained unaffected. These results indicated that the addition of PS $(2.66 \%)$ modified the film structure to such an extent that it could facilitate the permeation of water vapour. Loosening the compactness of the starch film structure due to PS vis-à-vis enhanced moisture permeation has also been described by Fama et al. (2005). Shen et al. (2010) and Flores et al. (2007) reported that with addition of less than $5 \%$ PS (w/w of starch), no significant changes in WVP were observed for sweet potato starch or tapioca starch films; however, when PS content was increased from $5 \%$ to $10 \%$, WVP for the former film increased considerably from $2.535 \times 10^{-10} \mathrm{~g} /($ s.m.Pa $)$ to $3.769 \times 10^{-10} \mathrm{~g} /(\mathrm{s} . \mathrm{m} . \mathrm{Pa})$. Besides starch, PS at different concentration levels has also been reported to increase the WVP of other polymeric films and coatings. Pranoto, Rakshit, and Salokhe (2005) and Park, Stan, Daeschel, and Zhao (2005) incorporated 15\% PS (w/w of chitosan) in chitosan film, Valencia-Chamorro et al. (2008) incorporated about 2\% PS in HPMClipid film solution, Park et al. (2005) included $30 \%$ PS (w/w of HPMC) in HPMC coating, and Vásconez et al. (2009) added $1.66 \%$ PS (w/w of starch-chitosan mixture) in a starch-chitosan film. All these reported increased WVP which could be attributed to a disruption of the crystalline structure of the homogeneous polymer network. 


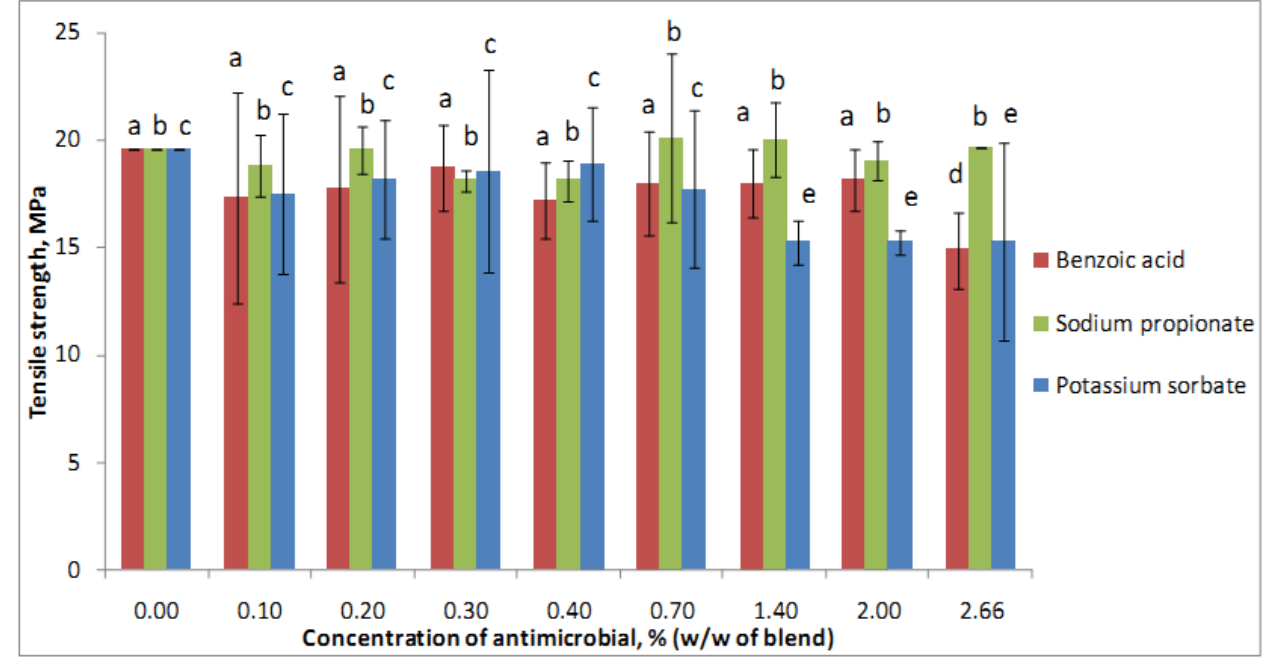

Figure 1: Effect of antimicrobials on tensile strength of starch films. Means with the same letter are not significantly different $(\mathrm{p}>0.05$ or 0.01$)$.

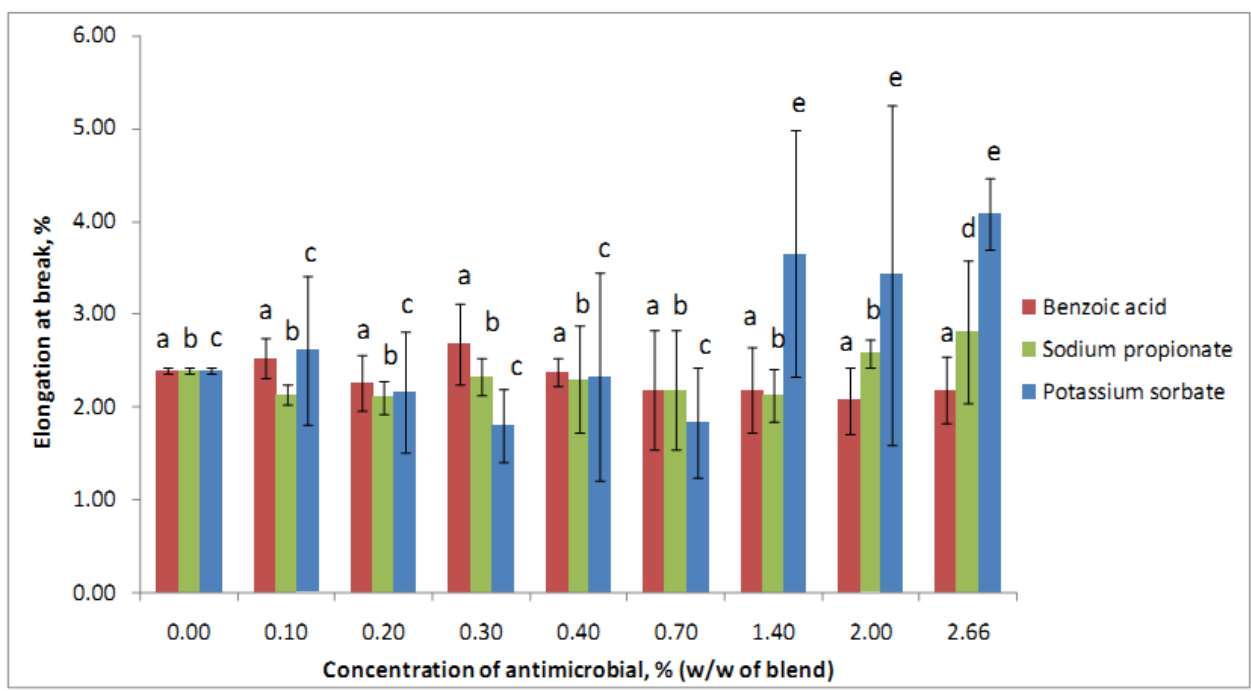

Figure 2: Effect of antimicrobials on elongation at break of starch films. Means with the same letter are not significantly different $(\mathrm{p}>0.05$ or 0.01$)$. 


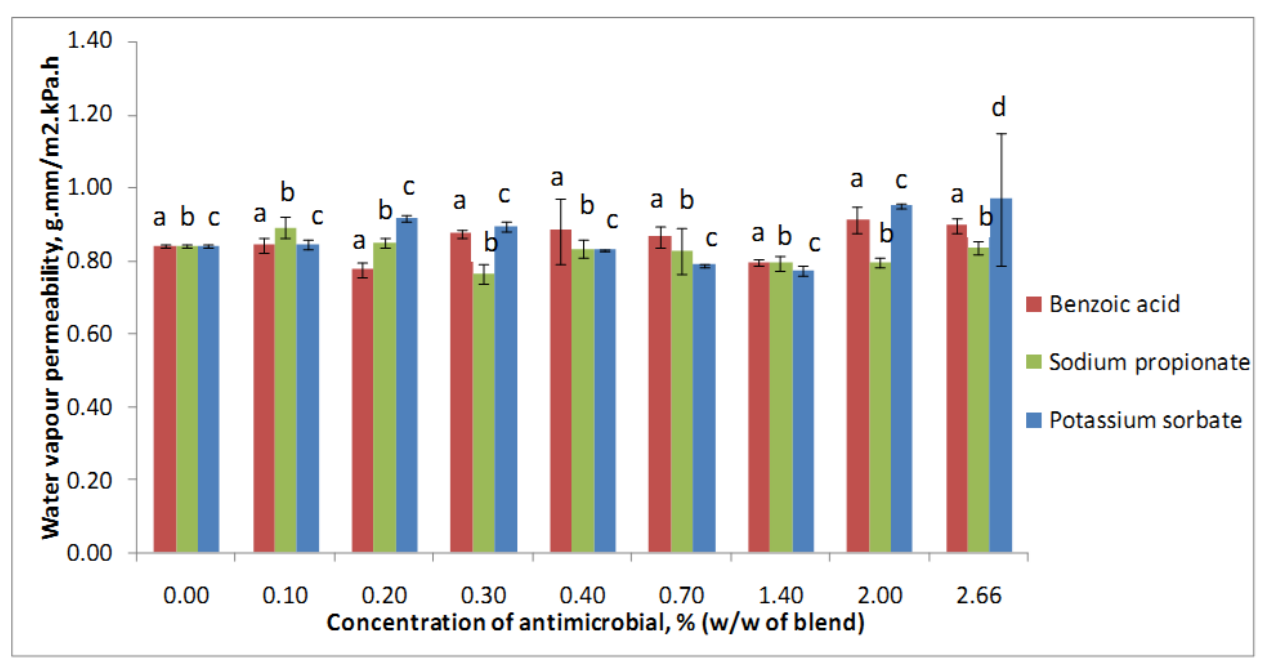

Figure 3: Effect of antimicrobials on water vapour permeability of starch films. Means with the same letter are not significantly different ( $\mathrm{p}>0.05$ or 0.01$)$.

\subsection{Optical properties}

Whiteness index (WI) of the films is shown in Figure 4. Irrespective of concentration, benzoic acid and sodium propionate decreased $(\mathrm{P}<0.01)$ the WI of the control film $(72.76 \pm 0.03)$. It was lowered to an average of $69.47 \pm 0.59(4.52 \%)$ for $\mathrm{BA}$ and $68.68 \pm 1.66(5.60 \%)$ for SP. For PS on the other hand, a significant decrease $(\mathrm{P}<0.01)$ from the control was observed to a mean of $65.79 \pm 0.72$ $(9.58 \%)$ for up to $0.40 \%$, followed by significant changes for each successive addition up to a value of $48.57 \pm 1.85$ at $2.66 \%$. This indicated that BA and SP exert small and comparable effects on the WI of corn starch film, while PS showed the highest reduction.

Antimicrobials were found to increase the YI of the treated samples compared with the control film (2.36 \pm 0.23$)$ (Figure 5). The YI increased significantly $(\mathrm{P}<0.01)$ to an average of $3.23 \pm 0.38$ $(\approx 37 \%$ increase $)$ for $\mathrm{BA}$ and $4.04 \pm 0.43(\approx 72 \%$ increase) for SP over the entire range of concentrations. On the contrary, there was no significant change in YI value up to $0.40 \%$ PS. However, beyond this level, the YI increased significantly $(\mathrm{P}<0.01)$ with increasing concentration of PS. This reached a maximum of $7.49 \pm 0.49$ for $2.66 \%$ addition. The starch and HPMC in the film might have under gone interaction with antimicrobials (Ofman et al., 2004; ValenciaChamorro et al., 2008), and possibly such interaction was responsible for development of yellow colour. The development of substantial YI due to interaction of citric acid and corn starch has been reported by Reddy and Yang (2010) whilst curing the citric acid crossed linked corn starch film. In addition to interaction, oxidative degradation of PS leading to development of polymerized product might be the reason for development of excessive yellow colour in the film (Jager, 2003; Schmidt, 2002).

Opacity of the films (Figure 6) was found to be unaffected $(\mathrm{P}>0.05)$ by $\mathrm{BA}$ incorporation up to $1.40 \%$; for $2 \%$, however, there was an increase $(\mathrm{P}<0.01)$ from $5.72 \pm 0.59$ (control) to $6.27 \pm 0.14$ i.e., about $9.60 \%$ increase. The subsequent increase for up to $2.66 \%$ was insignificant $(\mathrm{P}>0.05)$. For films with SP incorporated, the first significant increase $(\mathrm{P}<0.01)$ in opacity was seen for $0.30 \%$ addition. Between 0.30 and $2.66 \%$, it averaged $6.72 \pm 0.38$ (approximately $17.48 \%$ increase from the value of the control). Incorporation of PS on the other hand showed a significant decrease in opacity to an average of $5.09 \pm 0.20$, about an $11 \%$ decrease compared with the control film, for the entire range of 
concentration. The decrease in opacity meant an increase in transparency, which is desirable when the film is to be used as packaging material (Chen, Kuo, \& Lai, 2009). According to Chen et al. (2009) the transparency arises from the amorphous character of the film. The reduction in opacity in the present case due to the incorporation of PS might therefore be due to interaction with the biopolymers, producing a modified network structure. Film opacity has also been reported to be affected by interaction of starch with glycerol, which modifies the starch network (Mali, Grossmann, Garcia, Martino, \& Zaritzky, 2004). Dehghan, Badiei, and Behmadi (2009) indicated that although glycerol addition reduces the opacity of soy protein isolate films, its concentration does not have a significant correlation with this optical property.

Over the range of concentrations tested, the brightness index, Z\%, was reduced significantly $(\mathrm{P}<0.01)$ to mean of $76.93 \pm 0.16(\approx 1.46 \%$ decrease) for BA and $75.84 \pm 0.35(\approx 2.86 \%$ decrease) for SP compared with the control film $(78.07 \pm 0.16)$ (Figure 7$)$. For PS, the results were a bit different. Compared with the control, the $\mathrm{Z} \%$ lowered to an average value of $75.75 \pm 0.17$ for up to $0.70 \%$; up to this concentration, the trend was exactly similar to that of SP. However, at higher levels, the $\mathrm{Z} \%$ reduced $(\mathrm{P}<0.01)$ significantly at each successive level. Brightness index is a measure of surface brightness, and therefore all the antimicrobials reduce the brightness of the films. Among the three, PS when added more than $0.7 \%$ in the blend caused the highest reduction in surface brightness.

Thus, it was evident that if the amount of PS in film was $\geq 1.40 \%$ it lowered the TS and increased $\% \mathrm{E}$, but WVP was increased when the amount was increased to $2.66 \%$. When added at $2.66 \%$, $\mathrm{BA}$ reduced the TS but did not affect $\% \mathrm{E}$, whilst $\mathrm{SP}$ increased \% E but did not affect TS. Individually, these changes led to the reduction of some cohesive force in the film; this type of mismatch of TS and \% E has also been reported elsewhere (Das, 2008). It is worth mentioning that reports of film properties as affected by BA and SP are limited.

Regarding optical properties, all the three antimicrobials adversely affected the corn starch film by decreasing the WI, increasing YI, and re- ducing the surface gloss. Among these, PS most adversely affected the optical properties. However, PS reduced the opacity of the films by $11 \%$.

\section{Conclusions}

Depending on concentration, the antimicrobials benzoic acid, sodium propionate and potassium sorbate affected different parameters of the physico-mechanical properties of corn starchbased self-supporting edible film. Sodium propionate did not decrease the tensile strength and water vapour permeability but rather caused an improvement in elongation. Nonetheless, all of them showed undesirable effects by decreasing the whiteness index and surface gloss while increasing the yellowness index with potassium sorbate having the most adverse effect. Overall, sodium propionate appeared to be the best with minimum deterioration of film properties and, therefore, can be recommended for inclusion in film formulations as an antimicrobial agent.

\section{Acknowledgements}

Financial assistance from the Ministry of Environment and Forest, New Delhi, India (Grant No. $19 / 68 / 2005-\mathrm{RE})$ to the first author is acknowledged with thanks.

\section{References}

Cagri, A., Ustunol, Z., \& Ryser, E. (2001). Antimicrobial, mechanical, and moisture barrier properties of low $\mathrm{pH}$ whey protein-based edible films containing p-aminobenzoic or sorbic acids. Journal of Food Science, 66(6), 865-870. doi:10.1111/j.1365-2621.2001.tb15188.x

Campos, C. A., Gerschenson, L. N., \& Flores, S. K. (2011). Development of edible films and coatings with antimicrobial activity. Food and Bioprocess Technology, 4(6), 849-875. doi:10.1007/s11947-010-0434-1 


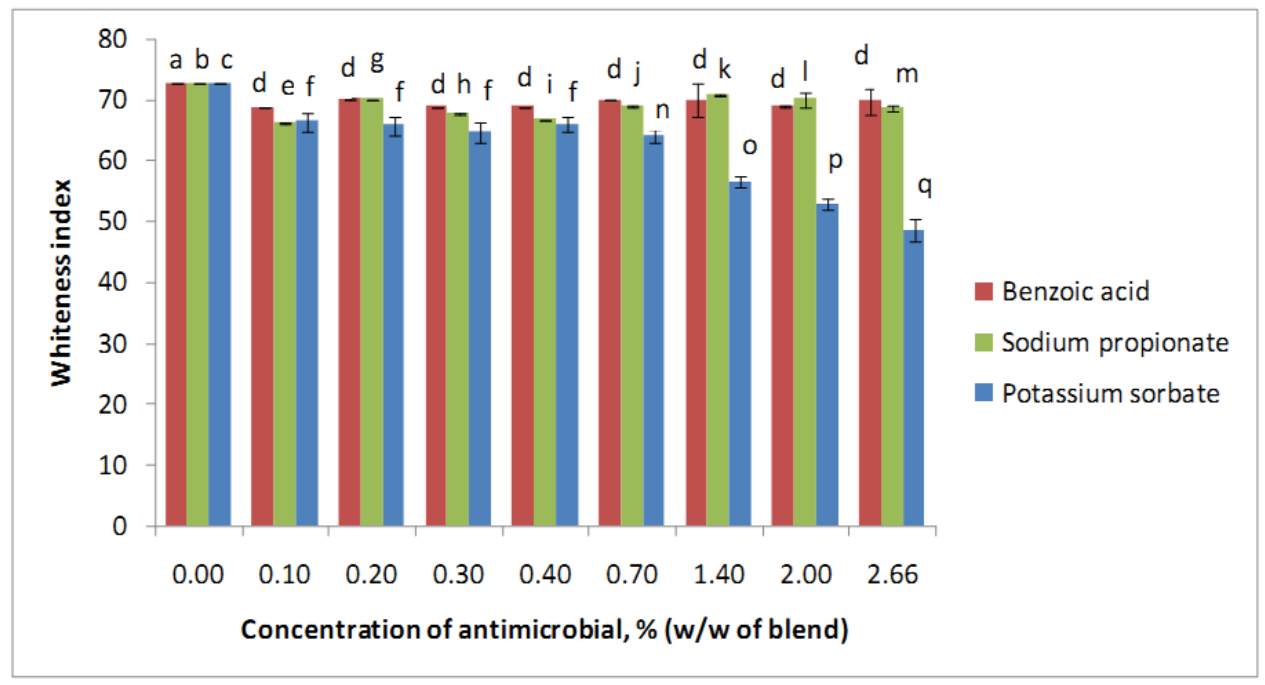

Figure 4: Effect of antimicrobials on whiteness index of starch films. Means with the same letter are not significantly different ( $\mathrm{p}>0.05$ or 0.01$)$.

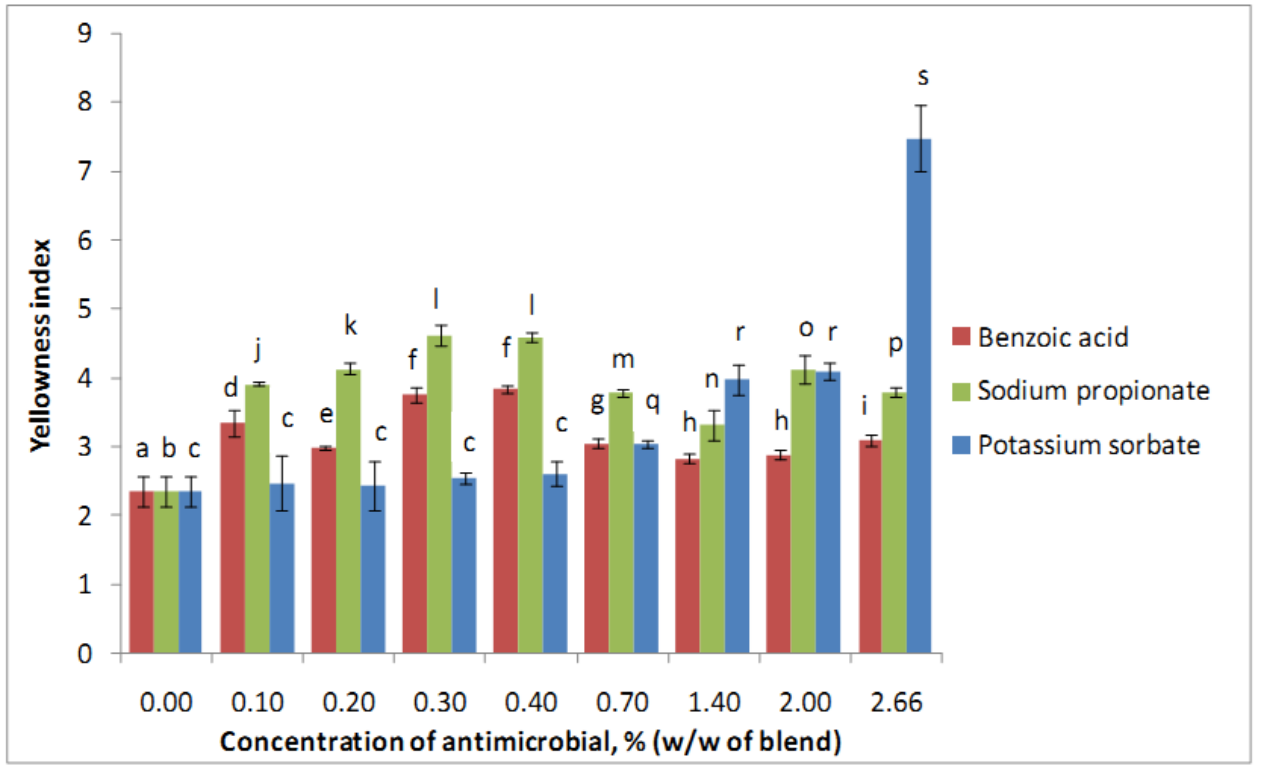

Figure 5: Effect of antimicrobials on yellowness index of starch films. Means with the same letter are not significantly different $(\mathrm{p}>0.05$ or 0.01$)$. 


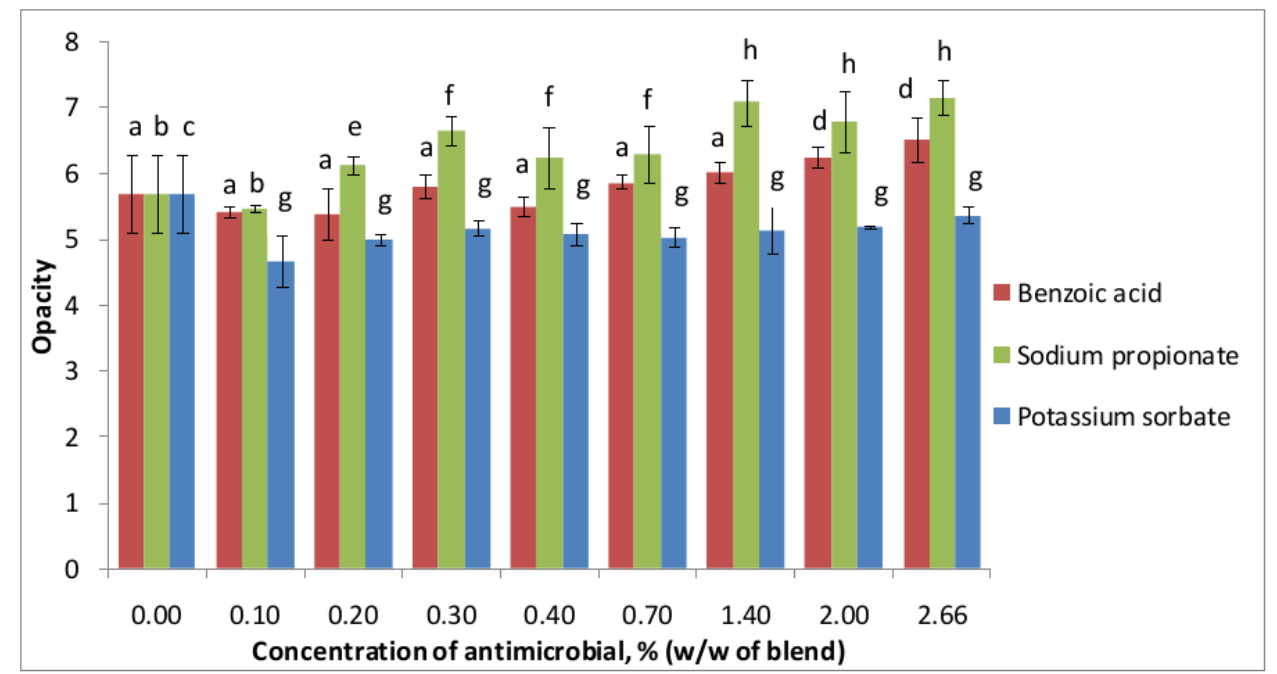

Figure 6: Effect of antimicrobials on opacity of starch films. Means with the same letter are not significantly different $(\mathrm{p}>0.05$ or 0.01$)$.

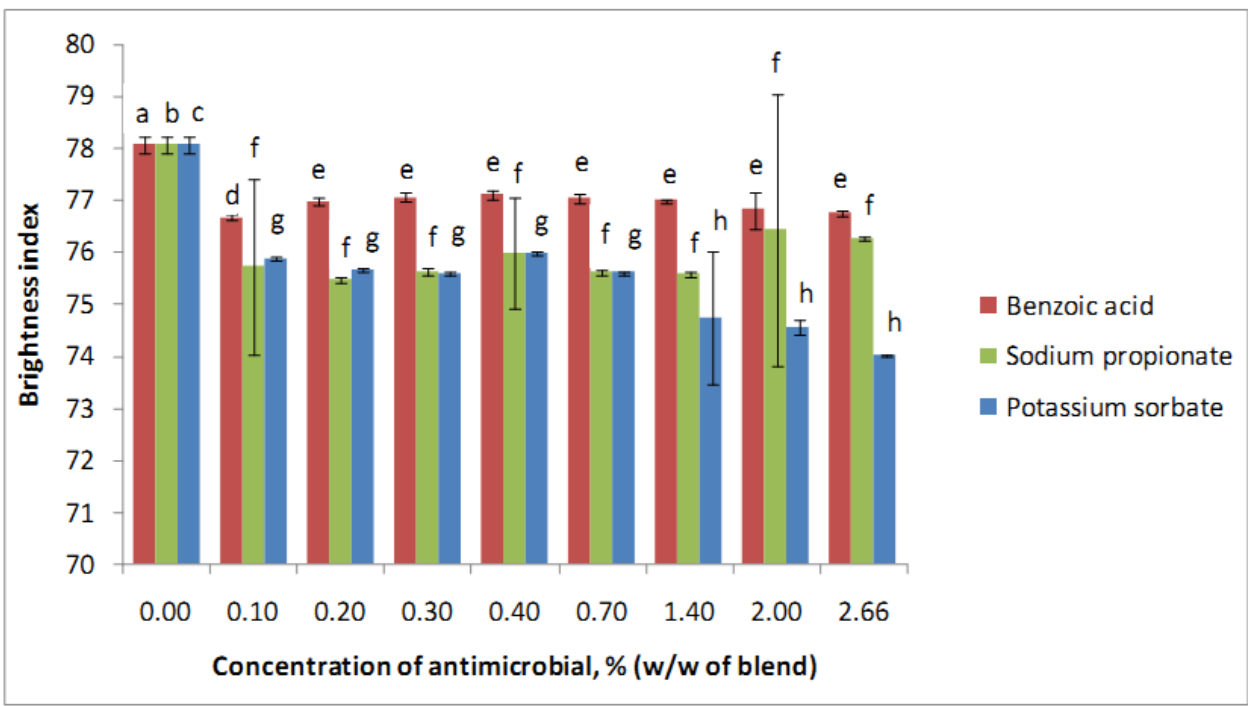

Figure 7: Effect of antimicrobials on brightness index of starch films. Means with the same letter are not significantly different $(\mathrm{p}>0.05$ or 0.01$)$. 
Chen, C.-H., Kuo, W.-S., \& Lai, L.-S. (2009). Rheological and physical characterization of film-forming solutions and edible films from tapioca starch/decolorized hsian-tsao leaf gum. Food Hydrocolloids, 23(8), 21322140. doi:10.1016/j.foodhyd.2009.05.015

Chowdhury, T., \& Das, M. (2010). Moisture sorption isotherm and isosteric heat of sorption characteristics of starch based edible films containing antimicrobial preservative. International Food Research Journal, 17(3), 601-614.

Das, M., \& Bal, S. (1999). Self-supporting edible films: a field of interest in modern food science. Processed Food Industry, 2(5), 2325.

Das, M., \& Namitha, P. K. (2010). Effect of incorporation of antioxidant/oxygen scavenger in self-supported potato starch based active packaging film on storability of some foods. in m. das \& p. namitha (eds.), american society of agricultural engineers. Paper presented in The American Society of Agricultural and Biological Engineers Annual International Meeting 2009, held at Reno, Nevada, 21-24 June (pp. 1109-1123), vol. 2. New York: Elsevier.

Das, M. (2008). Effect of screw speed and plasticizer on the torque requirement in single screw extrusion of starch based plastics and their mechanical properties. Indian Journal of Chemical Technology, 15(6), 555-559.

Dehghan, S. Z., Badiei, F., \& Behmadi, H. (2009). Effect of glycerol addition on the mechanical and physical properties of soy protein isolates film. Iranian Journal of Food Science and Technology, 6(1), 1-10.

Durango, A., Soares, N., \& Andrade, N. (2006). Microbiological evaluation of an edible antimicrobial coating on minimally processed carrots. Food Control, 17(5), 336341. doi:10.1016/j.foodcont.2004.10.024

Fama, L., Rojas, A., Goyanes, S., \& Gerschenson, L. (2005). Mechanical properties of tapioca-starch edible films containing sorbates. LWT-Food Science and Technology, 38(6), 631-639. doi:10.1016/j.lwt.2004.07. 024

Fazilah, A., Maizura, M., \& Norziah, M. H. (2006). Antimicrobial activity and physi- cal properties of sago starch-alginate edible film incorporate with lemon grass essential oil. In Fook Yee Chye \& Jau Shya Lee (Eds.), Current Research in Food Science and Nutrition. Paper presented at National Conference of Food Science and Nutrition, held at University of Malaysia Sabah, from 13-14 December (pp. 32), Kota Kinabalu Sabah: Universiti Malaysia Sabah.

Flores, S., Fama, L., Rojas, A. M., Goyanes, S., \& Gerschenson, L. (2007). Physical properties of tapioca-starch edible films: influence of filmmaking and potassium sorbate. Food Research International, 40(2), 257265. doi:10.1016/j.foodres.2006.02.004

Garcia, M., Martino, M., \& Zaritzky, N. (1998). Plasticized starch-based coatings to improve strawberry (Fragaria $x$ Ananassa) quality and stability. Journal of Agricultural and Food Chemistry, 46(9), 37583767. doi:10.1021/jf980014c

Gomez, K. A., \& Gomez, A. A. (1984). Statistical procedures for agricultural research. Singapore: John Wiley and Sons Inc.

Jager, M. (2003). Method for inhibition of sorbate-induced brown discolorations in cosmetic compositions and foodstuffs. US Patent 6,592,880. Google Patents.

Kechichian, V., Ditchfield, C., Veiga-Santos, P., \& Tadini, C. C. (2010). Natural antimicrobial ingredients incorporated in biodegradable films based on cassava starch. $L W T-$ Food Science and Technology, 43(7), 10881094. doi:10.1016/j.lwt.2010.02.014

Khairuddin, N., Razi, M., Radhiah, A., \& Muhamad, I. I. (2005). Antimicrobial (am) effects of strach-based film incorporated with lysozymes and lauric acid. Paper presented at $4^{\text {th }}$ Food Science and Technology Seminar, held at Penang, Malaysia, 12-14 September 2005.

Maizura, M., Fazilah, A., Norziah, M. H., \& Karim, A. A. (2007). Antibacterial activity and mechanical properties of partially hydrolyzed sago starch-alginate edible film containing lemongrass oil. Journal of Food Science, 72(6), C324-C330. doi:10.1111/j. 1750-3841.2007.00427.x

Mali, S., Grossmann, M., Garcia, M., Martino, M., \& Zaritzky, N. (2004). Barrier, mechan- 
ical and optical properties of plasticized yam starch films. Carbohydrate Polymers, 56(2), 129-135. doi:10.1016/j . carbpol . 2004.01.004

Ninomiya, H., Suzuki, S., \& Ishii, K. (1992). Edible film and method of making same. US Patent 5,089,307. Google Patents.

Nisperos-Carriedo, M. O. (1994). Edible coatings and films based on polysaccharides. In J. M. Krochta, E. A. Baldwin, \& M. O. Nisperos-Carriedo (Eds.), Edible coatings and films to improve food quality (pp. 192-219). Lanchester: Technomic Publishing Co.

Ofman, M., Campos, C., \& Gerschenson, L. (2004). Effect of preservatives on the functional properties of tapioca starch: analysis of interactions. Lebensmittel-wissenschaft Und-technologie-food Science and Technology, 37(3), 355-361. doi:10.1016/j.lwt. 2003.09.010

Park, S., Stan, S., Daeschel, M., \& Zhao, Y. (2005). Antifungal coatings on fresh strawberries (Fragaria $x$ Ananassa) to control mold growth during cold storage. Journal of Food Science, 70 (4), M202-M207.

Patel, S., \& Thanawala, N. (2008). Water soluble film based package, process and apparatus for sealing said package. WO Patent 2,008,068,779.

Pranoto, Y, Rakshit, S., \& Salokhe, V. (2005). Enhancing antimicrobial activity of chitosan films by incorporating garlic oil, potassium sorbate and nisin. LWT-Food Science and Technology, 38(8), 859-865. doi:10.1016/j.lwt.2004.lwt.2004.09.014

Reddy, N., \& Yang, Y. (2010). Citric acid crosslinking of starch films. Food Chemistry, 118(3), 702-711. doi:10.1016/j.foodchem. 2009.05.050

Salleh, E., \& Muhamad, I. I. (2007). Mechanical properties and antimicrobial analysis of antimicrobial starch-based film. Paper presented at: International Conference on Advancement of Materials and Nanotechnology, held at Langkawi, Kedah, 29 May-1 June 2007.

Salleh, E., Muhamad, I. I., \& Khairuddin, N. (2009). Structural characterization and physical properties of antimicrobial (am) starch-based films. World Academy of Science, Engineering and Technology, 55, 432440.

Schmidt, R. (2002). Method for suppressing sorbate-and/or sorbic acid-induced discoloration. US Patent 6,495,718. Google Patents.

Schou, M., Longares, A., Montesinos-Herrero, C., Monahan, F., O'Riordan, D., \& O'Sullivan, M. (2005). Properties of edible sodium caseinate films and their application as food wrapping. LWT-Food Science and Technology, 38(6), 605-610. doi:http://dx.doi.org/ 10.1016/j.lwt.2004.08.009

Shen, X. L., Wu, J. M., Chen, Y., \& Zhao, G. (2010). Antimicrobial and physical properties of sweet potato starch films incorporated with potassium sorbate or chitosan. Food Hydrocolloids, 24 (4), 285-290. doi:10. 1016/j.foodhyd.2009.10.003

Valencia-Chamorro, S. A., Palou, L., Del Rio, M. A., \& Perez Gago, M. B. (2008). Inhibition of Penicillium digitatum and Penicillium italicum by Hydroxypropyl Methylcellulose-Lipid Edible Composite Films Containing Food Additives with Antifungal Properties. Journal of Agricultural and Food Chemistry, 56(23), 11270-11278. doi:10.1021/jf802384m

Vásconez, M. B., Flores, S. K., Campos, C. A., Alvarado, J., \& Gerschenson, L. N. (2009). Antimicrobial activity and physical properties of chitosan-tapioca starch based edible films and coatings. Food Research International, 42(7), 762-769.

Yang, R., Fuisz, R., Myers, G., \& Fuisz, J. (2004). Packaging and dispensing of rapid dissolve dosage form. WO Patent 2,004,009,445. 